\title{
RENAL BLOOD FLOW IN WOMEN WITH HYPERTENSION AND RENAL IMPAIRMENT
}

\author{
By LEON C. CHESLEY AND ELIZABETH R. CHESLEY
}

(From the Department of Biochemistry, Margaret Hague Maternity Hospital, Jersey City)

(Received for publication December 27, 1939)

Spontaneous hypertension in man has been divided into two main categories-the renal and nonrenal. Renal hypertension has been considered to arise secondarily to a kidney lesion or deficiency, while the non-renal (primary or essential) hypertension has been thought to exist without underlying kidney pathology (Allbutt, Huchard, Janeway; cited by Fishberg (1)).

Goldblatt (2), and others using his method, have produced an experimental hypertension in dogs and monkeys by partial occlusion of the main renal arteries. Hyperpiesia in conjunction with mechanical obstruction to the main renal arterial blood flow has been described as a clinical entity ( 3 , and others), but nature's imitation of the experimental method is probably unusual. When interference with the renal blood flow exists, it is more usually to be found in the arterioles, glomerular capillaries, and peritubular blood vessels (as in urinary back pressure).

Many studies have been made of the renal function in patients with " essential " hypertension and, with the development of each new test more sensitive than its predecessors, the field has been reinvestigated. The characteristic finding, in the early stages of the hypertension at least, has been " normal " kidney function as measured by the test. under consideration. However, the tests have not been delicate enough to give the crucial answer, as will be discussed below. Recently, Smith, Goldring and Chasis (4) have defined the conditions under which the diodrast clearance is a measure of the renal plasma flow; at low plasma levels of diodrast, the renal extraction ratio is very close to 1 in normal man. While a low diodrast clearance might be suspect on the ground that an impairment in renal efficiency could change the extraction ratio, the clearance will always reflect the lowest possible volume of plasma which could have perfused the kidney during the clearance period. A normal diodrast clearance, therefore, must mean a normal plasma (and whole blood) flow through the kidneys during the test.

In the present report, we shall describe our measurements of renal blood flow in patients with considerable renal impairment with and without hypertension, and in patients with " essential " hypertension, some of whom had toxemia of pregnancy as the initial phase of the permanent hyperpiesia. The questions chiefly to be considered are whether hypertension is always accompanied by a decrease in the total renal blood flow, and whether diminished renal blood flow is always accompanied by hypertension. Some inferences will be drawn as to the site and nature of vascular changes in the kidney itself.

\section{MATERIAL AND METHODS}

Ten patients with renal impairment were drawn from the postpartum toxemia clinic. By a "patient with renal impairment" we mean one in whom the urea clearance is consistently below 60 per cent of average normal, regardless of the cause.

The essential hypertension cases are divided into 2 groups. The post-toxemic group of 16 patients was taken from the postpartum toxemia clinic. The other group of 11 subjects had no background of toxemia. These latter were drawn from the wards of the Jersey City Medical Center. By "essential hypertension" we mean the occurrence of increased blood pressure (usually marked) with minimal or no proteinuria, edema or hematuria, and with the urea clearance consistently above 70 per cent of average normal. Patients without a history of toxemia of pregnancy denied such history by name and by symptoms. In 2 cases it was possible to corroborate the patients' denials by contact with physicians, 2 patients had never been pregnant, 1 was a man, and all others were at least 12 years postpartum.

The effective renal blood flow was calculated by dividing the plasma fraction into the plasma clearance of diodrast (4). This measurement will hereinafter be called simply the "renal blood flow." All figures are corrected to the ideal surface area of $1.73 \mathrm{sq}$. $\mathrm{m}$. Details of the procedure, slightly modified from the description given by Smith, Goldring and Chasis (4), have been outlined in previous publications $(5,6)$. Briefly, a 10 per cent solution of dextrose, containing $1 \mathrm{ml}$. of 35 per cent diodrast per $100 \mathrm{ml}$, is given intravenously at 
the rate of $10 \mathrm{ml}$. per minute for 10 minutes. The rate of infusion is then cut down to $4 \mathrm{ml}$. per minute, at which rate it is continued throughout the test. About 30 to 40 minutes after the beginning of the infusion the bladder is washed out twice with physiological saline, using a special multi-opening catheter. Urine collections are then made at intervals of about $\mathbf{3 0}$ minutes, the bladder being washed out twice each time. Usually 4 urine collections are made. At 45-minute intervals during the test, blood samples (oxalated) are collected for analysis; 4 samples are taken.

Diodrast in plasma and urine was analyzed as iodine, using a modification of Kendall's method $(5,6)$. All determinations were done in duplicate.

Simultaneous determinations were made of the plasma clearance of urea, using Van Slyke's manometric methods (7). The hematocrits were determined in vaccine tubes designed by MacKay for protein estimation (7).

\section{RESULTS}

Since our first publication (5), we have done diodrast clearances on 13 additional normal women. The renal blood flow in the series of 30 women ranges from 694 to $1233 \mathrm{ml}$., and averages $850 \mathrm{ml}$. per minute per 1.73 sq. m. body surface. The standard deviation is $113 \mathrm{ml}$., and the standard error of the mean is $20.6 \mathrm{ml}$. Assuming that 60 per cent of the filtered urea is excreted in the final urine (in maximal urea clearances), a rough estimation of the glomerular filtration may be made from the urea clearance. Dividing this estimated filtration by the diodrast clearance (plasma flow) will give an approximation to the filtration fraction (i.e. the proportion of the perfusing plasma which is filtered through the glomerular capillaries). In our normal series, the filtration fraction thus estimated varies from 15.2 to 24.5 per cent, and averages 20.4 per cent. The standard deviation is 3.0 per cent, and the standard error of the mean is $0.65 ; 21$ cases are analyzed. ( Two atypical cases with very high urea clearances are not included.) All data for normal subjects are given in Table $\mathrm{I}$.

Our filtration fraction for normal women is somewhat higher than Smith's (8), which averaged 17.7 per cent for men. In this connection, it is interesting to note that our average plasma urea clearance for women is identical with Smith's average for men, at $70 \mathrm{ml}$. per minute. At the same time the renal blood flow in our women is considerably below the level which Smith reports for men ( $846 \mathrm{ml}$. and $1275 \mathrm{ml}$., respectively). This
TABLE I

Plasma clearances of diodrast and urea, urea extraction ratios, estimated filtration fractions, and renal blood flows in 30 normal women

Filtration fraction estimated from maximal urea clearance, which is assumed to be 0.60 of the glomerular filtration rate.

\begin{tabular}{c|c|c|c|c}
\hline \hline Plasma clearance of & $\begin{array}{c}\text { Urea } \\
\text { extraction } \\
\text { ratio }\end{array}$ & $\begin{array}{c}\text { Filtration } \\
\text { fraction }\end{array}$ & $\begin{array}{c}\text { Renal } \\
\text { blood flow }\end{array}$ \\
\hline Diodrast & Urea & per cent & per cent & $\begin{array}{c}\text { ml. per } \\
\text { minute }\end{array}$ \\
\hline ml. per minute & $\begin{array}{c}\text { ml. per } \\
\text { minute }\end{array}$ & per & ming \\
\hline
\end{tabular}

PREgNANT, NEAR TERM

\begin{tabular}{|c|c|c|c|c|c|}
\hline & $\begin{array}{l}520 \\
848 \\
560 \\
513 \\
607 \\
672 \\
593 \\
568 \\
536 \\
521 \\
619 \\
674 \\
538 \\
613 \\
479\end{array}$ & $\begin{array}{c}(91.0)^{*} \\
(138.0)^{*} \\
64.2 \\
47.5 \\
\\
\\
\\
82.8 \\
67.8 \\
50.5 \\
96.4 \\
70.6 \\
74.0 \\
70.4\end{array}$ & $\begin{array}{c}(11.6)^{*} \\
(11.2)^{*} \\
8.6 \\
6.9 \\
\\
\\
10.2 \\
8.8 \\
6.9 \\
9.9 \\
8.6 \\
8.0 \\
9.5\end{array}$ & $\begin{array}{c}(29.2)^{*} \\
(28.9)^{*} \\
19.1 \\
15.5 \\
\\
\\
24.2 \\
21.1 \\
16.2 \\
23.8 \\
21.9 \\
20.1 \\
24.5\end{array}$ & $\begin{array}{r}787 \\
1233 \\
793 \\
694 \\
886 \\
995 \\
833 \\
812 \\
770 \\
733 \\
848 \\
971 \\
821 \\
925 \\
742\end{array}$ \\
\hline \multicolumn{6}{|c|}{ NON-PREGNANT } \\
\hline & $\begin{array}{l}461 \\
531 \\
542 \\
485 \\
676 \\
601 \\
554 \\
501 \\
524 \\
461 \\
721 \\
493 \\
459 \\
525 \\
607\end{array}$ & $\begin{array}{l}49.4 \\
48.1 \\
71.0 \\
97.4 \\
61.0 \\
65.6 \\
61.3 \\
71.3 \\
\\
98.0 \\
60.9 \\
45.9 \\
75.4\end{array}$ & $\begin{array}{r}6.6 \\
5.7 \\
9.3 \\
9.4 \\
5.8 \\
7.2 \\
7.7 \\
8.5 \\
10.0 \\
8.8 \\
6.3 \\
9.3\end{array}$ & $\begin{array}{l}17.7 \\
15.2 \\
24.4 \\
24.0 \\
17.0 \\
19.7 \\
17.3 \\
22.7 \\
\\
22.7 \\
20.6 \\
16.7 \\
23.9\end{array}$ & $\begin{array}{r}752 \\
792 \\
851 \\
769 \\
1029 \\
1049 \\
918 \\
807 \\
846 \\
738 \\
983 \\
693 \\
731 \\
811 \\
886\end{array}$ \\
\hline $\begin{array}{l}\text { Mean } \\
\sigma \\
\text { S.E. } \bar{x}\end{array}$ & \begin{tabular}{|l}
567 \\
82.5 \\
15.1
\end{tabular} & $\begin{array}{r}70.0 \\
15.1 \\
3.3\end{array}$ & $\begin{array}{l}8.3 \\
1.6 \\
0.35\end{array}$ & $\begin{array}{c}20.4 \\
3.0 \\
0.65\end{array}$ & $\begin{array}{c}850 \\
113 \\
20.6\end{array}$ \\
\hline
\end{tabular}

* Not averaged because the blood urea was considered to be erroneously low; plasma urea N/N.P.N. ratios less than 0.28 .

necessarily means that in our women the urea extraction ratio is higher than in Smith's men. This is effected by two means: the filtration fraction is higher in women, and the hematocrit is lower. That is, more of the woman's blood is plasma, and a larger proportion of plasma is filtered at the glomerulus. 
Since our findings in cases of hypertension following toxemia of pregnancy usually showed certain qualitative as well as quantitative differences from the results reported by Smith (8) for hypertension in men, we have measured the renal blood

TABLE II

\section{Hypertension, renal impairment, and renal blood flow}

Blood pressure readings made during tests. Filtration fraction approximated from maximal urea clearance which is assumed to be 0.60 of glomerular filtration. "Renal ischemia," in percentage, represents the deficit in renal blood flow as compared with average normal of $850 \mathrm{ml}$. per minute.

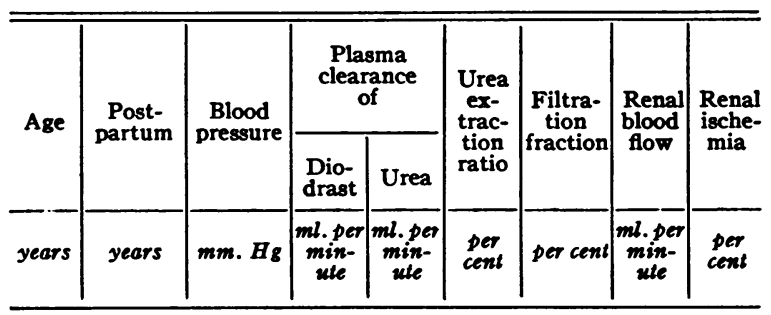

A. HYPERTENSIVES WITHOUT HISTORY OF TOXEMA OF PREGNANCY

\begin{tabular}{|c|c|c|c|c|c|c|c|c|}
\hline $\begin{array}{l}65 \\
50 \\
22 \\
29 \\
49 \\
50 \\
50 \\
49 \\
47 \\
48 \\
54\end{array}$ & $\begin{array}{l}\mathrm{N}^{*} \\
\mathrm{~N}^{*} \\
\sigma^{*} \\
6.2 \\
25.0 \\
12.0 \\
22.0 \\
20.0 \\
21.0 \\
17.0 \\
19.0\end{array}$ & $\begin{array}{l}216 / 100 \\
224 / 108 \\
150 / 110 \\
240 / 160 \\
186 / 110 \\
210 / 110 \\
206 / 110 \\
160 / 110 \\
204 / 110 \\
234 / 134 \\
230 / 145\end{array}$ & $\begin{array}{l}273 \\
401 \\
96 \dagger \\
218 \\
188 \\
530 \\
557 \\
328 \\
543 \\
322 \\
401\end{array}$ & $\begin{array}{l}54.1 \\
79.6 \\
19.0 \dagger \\
599.4 \\
34.0 t \\
67.6 \\
72.7 \\
54.4 \\
77.0 \\
49.7 \\
60.0\end{array}$ & $\begin{array}{r}12.9 \\
12.6 \\
12.4 \\
16.2 \\
10.8 \\
7.8 \\
8.5 \\
11.7 \\
9.0 \\
9.4 \\
8.8\end{array}$ & $\begin{array}{l}33.0 \\
33.1 \\
32.8 \\
45.4 \\
31 .+ \\
21.3 \\
21.7 \\
27.6 \\
23.6 \\
25.7 \\
25.0\end{array}$ & $\begin{array}{l}420 \\
629 \\
153+ \\
366 \\
315 \\
868 \\
860 \\
467 \\
859 \\
531 \\
685\end{array}$ & $\begin{array}{r}51 \\
26 \\
74 \\
57 \\
63 \\
0 \\
0 \\
45 \\
0 \\
36 \\
20\end{array}$ \\
\hline
\end{tabular}

B. HYPERTENSIVES WITH HISTORY OF TOXEAIA OF PREGNANCY

\begin{tabular}{l|l|l|l|l|r|r|r|r}
\hline 41 & 0.1 & $170 / 106$ & 358 & 68.0 & 13.6 & 32.0 & 503 & 41 \\
30 & 1.3 & 192120 & 434 & 48.1 & 6.9 & 18.5 & 700 & 18 \\
34 & 3.2 & $152 / 90$ & 403 & 52.0 & 8.7 & 21.4 & 597 & 30 \\
27 & 3.4 & $180 / 130$ & 538 & 58.4 & 7.1 & 18.1 & 828 & 2 \\
48 & 4.7 & 16890 & 430 & 43.2 & 5.6 & 16.8 & 765 & 10 \\
37 & 2.2 & $170 / 120$ & 437 & 70.2 & 10.0 & 26.9 & 705 & 17 \\
48 & 3.6 & 15090 & 517 & 62.2 & 7.6 & 20.0 & 815 & 4 \\
38 & 5.5 & $210 / 140$ & 376 & 38.3 & 6.7 & 17.0 & 567 & 33 \\
40 & 2.0 & $240 / 126$ & 450 & 57.9 & 9.0 & 21.5 & 648 & 24 \\
39 & 1.8 & 2201120 & 377 & 40.5 & 6.8 & 17.9 & 599 & 30 \\
48 & 5.0 & $200 / 110$ & 382 & 38.6 & 6.6 & 16.8 & 585 & 31 \\
40 & 4.0 & 190150 & 349 & 47.5 & 9.3 & 22.7 & 512 & 40 \\
30 & 0.6 & $180 / 120$ & 454 & 53.2 & 7.7 & 19.5 & 690 & 19 \\
24 & 0.1 & $170 / 100$ & 531 & 63.0 & 8.2 & 19.8 & 766 & 10 \\
35 & 1.3 & 14090 & 392 & 54.9 & 9.0 & 23.3 & 608 & 28 \\
43 & 8.0 & $214 / 140$ & 160 & 30.4 & 8.6 & $(31.4) 8$ & 350 & 59 \\
\hline
\end{tabular}

C. PATIENTS WITH RENAL IMPAIRMENT

\begin{tabular}{|c|c|c|c|c|c|c|c|c|}
\hline $\begin{array}{l}26 \\
20 \\
28 \\
39 \\
27\end{array}$ & $\begin{array}{r}0.3 \\
2.4 \\
1.2 \\
3.3 \\
\text { ante- }\end{array}$ & $\begin{array}{r}90 / 60 \\
100 / 60 \\
150 / 94 \\
70 / 50 \\
100 / 60\end{array}$ & $\begin{array}{l}300 \\
330 \\
184 \\
275 \\
156\end{array}$ & $\begin{array}{l}34.0 \\
38.5 \\
17.7 \\
34.7 \\
21.8\end{array}$ & $\begin{array}{r}8.3 \\
7.8 \\
6.4 \\
8.0 \\
10.8\end{array}$ & $\begin{array}{l}18.8 \\
19.4 \\
15.9 \\
21.0 \\
23.3\end{array}$ & $\begin{array}{l}413 \\
495 \\
279 \\
433 \\
201\end{array}$ & $\begin{array}{l}51 \\
41 \\
67 \\
49 \\
76\end{array}$ \\
\hline 28 & $\begin{array}{l}\text { partum } \\
\text { ante- }\end{array}$ & $155 / 100$ & 70 & 9.5 & 9.7 & 22.6 & 98 & 88 \\
\hline $\begin{array}{l}34 \\
32 \\
23 \\
43\end{array}$ & $\begin{array}{l}2.8 \\
3.5 \\
0.1 \\
0.1\end{array}$ & $\begin{array}{l}120 / 80 \\
120 / 90 \\
200 / 130 \\
156 / 90\end{array}$ & $\begin{array}{l}219 \\
435 \\
290 \\
312\end{array}$ & $\begin{array}{l}25.1 \\
36.0 \\
29.4 \\
32.8\end{array}$ & $\begin{array}{l}7.4 \\
5.7 \\
6.8 \\
7.5\end{array}$ & $\begin{array}{l}19.1 \\
13.9 \\
16.8 \\
17.5\end{array}$ & $\begin{array}{l}338 \\
635 \\
432 \\
439\end{array}$ & $\begin{array}{l}60 \\
25 \\
49 \\
48\end{array}$ \\
\hline
\end{tabular}

* Nulligravida.

$\dagger$ Left kidney only (right kidney had undergone sympathetic denervation).

†tandard urea clearance.

$\$$ High because of very high hematocrit ( 55 per cent). flow in 11 hypertensive patients who had no toxemic pregnancy. In these few cases, with 3 exceptions, our data confirm Smith's findings. As shown in Section A of Table II, a diminished blood flow is present in all but 3 cases. Moreover, the filtration fraction is characteristically elevated (though not in the subjects with normal renal blood flow). Smith has explained renal ischemia together with a high filtration fraction on the basis of efferent glomerular arteriolar constriction. As he has pointed out, this maintenance of a high filtration fraction accounts for the frequent finding of "normal" renal function, as shown by the usual tests, even with a great deficit in the volume of blood perfusing the kidney.

The findings in the majority of our post-toxemic hypertensive patients do not conform with the above conditions (Section B of Table II). In most cases there is a diminution in the renal blood flow as compared with the average normal. Yet 8 of the 16 values are in the normal range as given by the normal mean minus twice its standard deviation. Significantly, the filtration fraction is not increased (2 exceptions). In other words, the urea clearance parallels closely the renal blood flow as calculated from the diodrast clearance. In a few of these cases, the urea clearance (Table II) is subnormal; however, in nearly all of these patients the urea clearance is usually 70 per cent (49 ml. per minute) or more of normal.

Two of the 4 hypertensive patients showing absolutely no diminution in total renal blood flow ( 3 in Section A and 1 in Section B of Table II) had, at the time of the test, blood pressure readings far lower than the usual levels observed. The first patient's pressure often exceeded 300 $\mathrm{mm}$. $\mathrm{Hg}$ in the systolic and $150 \mathrm{~mm}$. $\mathrm{Hg}$ in the diastolic readings. The fourth patient's pressure usually ran about 270/160. During the tests, under basal conditions, the blood pressures in these women were $210 / 110$ and $180 / 130$, respectively. Perhaps if the renal blood flows were measured at another time, with the higher blood pressures, some deficit might be found (if increased tension did not compensate for the narrowed arterioles and maintain normal renal blood flow). In both of these cases, the filtration fraction was normal at the time of observation. The blood pressures of the other patients were at the usual levels, even after bed rest of several days. 


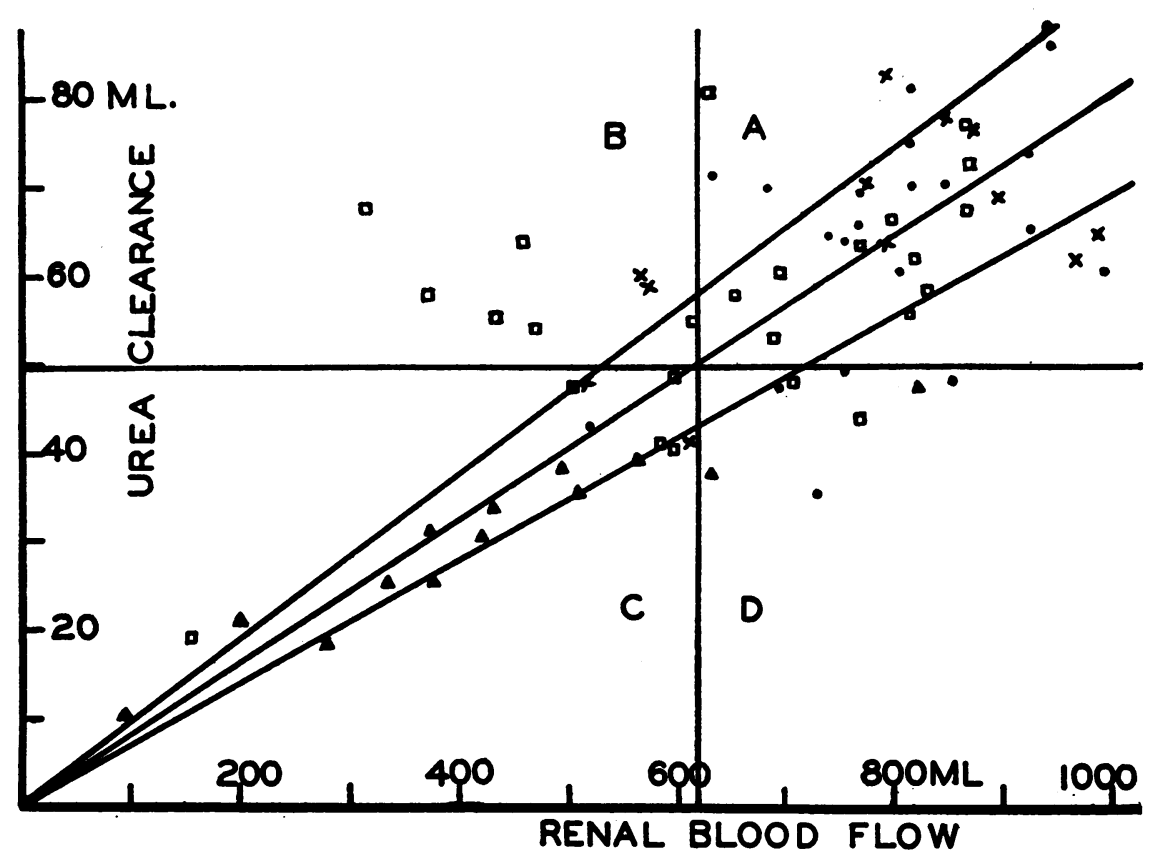

Fig. 1. The Relationship Between the Urea Clearance and the Renal BLood Flow

The graph is divided into 4 squares by lines representing the lower normal limits of urea clearance ( $49 \mathrm{ml}$. per minute) and of the renal blood flow $(625 \mathrm{ml}$. per minute). See text for explanation.

- Normal women.

$\times$ Preeclamptic and eclamptic women (previously published (6)).

$\square$ Hypertensive women.

$\Delta$ Women with renal impairment (3 cases published (6)).

Data for the previously published cases are not presented in Table II. Seventeen of the normal subjects formed the basis for an earlier publication (5).

One may now ask whether diminished renal blood flow, when present, must cause hypertension. (We are not equating diminished renal blood flow with renal ischemia. See Discussion.) As an approach to this question we have measured the diodrast clearance in a selected group of 10 patients with definite renal impairment, the majority of whom maintain normal blood pressures. As stated above, the renal impairment in different cases is attributable to diverse causes. For the moment it will be assumed that the diodrast clearance is complete in these patients, and is therefore a measure of the renal plasma flow. The observations on these patients are shown in Section $C$ of Table II. In every case there is a marked diminution in the diodrast clearance and presumably, therefore, in the renal blood flow. The filtration fraction was always found to be in the normal range. In the cases showing increased blood pressure, the filtration fraction was normal or even a little low. The urea clearance, therefore, closely parallels the diodrast clearance and renal blood flow over the whole range down to about 10 per cent of normal function.

A comparison of the urea clearance with the renal blood flow (calculated from the diodrast clearance) is plotted in Figure 1. The 70 subjects represented comprise normals, as well as patients with toxemia of pregnancy $(5,6)$, posttoxemic hypertension, chronic nephritis, pyelonephritis, and post-toxemic renal damage. As may be seen from the graph, the parallelism is good, and the urea clearance follows fairly closely the renal blood flow. In quantitative terms, the coefficient of correlation $(r)$ between renal blood flow and urea clearance is 0.79 for all of these subjects. (A few subjects with very high urea clearances, up to 200 per cent, had correspondingly 
high renal blood flows; these are not shown in the graph.)

Figure 1 has been subdivided into 4 squares by representing the lower limits of normal urea clearance and of renal blood flow. These lower normal limits have been set by subtracting twice the standard deviation from the mean. The positive lines, originating at zero, describe the average ratio between the urea clearance and renal blood flow (middle line) and include points falling within plus or minus 15 per cent of the average ratio (outside lines). It will be seen that in most cases one may predict, within 15 per cent, the renal blood flow from the urea clearance. The graph might be further subdivided into 10 fields, with a different interpretation for a point falling in any one of these fields. For the sake of brevity, we shall consider only the 4 major squares. $A$ is the field of normal kidney function. $B$ represents diminished renal blood flow with normal urea clearance (normal filtration), high filtration fraction, and probable efferent glomerular arteriolar constriction. Smith's (8) male hypertensives fall in this field, as do all but 3 of our hypertensive women who had no history of toxemia of pregnancy. Two cases of toxemia of pregnancy, 1 an active eclamptic, also fall in this area. $C$ includes cases of renal impairment. When the points fall above the upper positive line originating at zero, constriction of the efferent glomerular arteriole is present and compensates in part for the diminution in renal blood flow. Essential hypertension patients with renal impairment would conform to the latter description. $D$ describes cases in which the urea clearance is disproportionately low as compared with the renal blood flow. In our series, the patients falling in this category were varied. There were 4 normals presumably showing low variations in the urea clearance, which does fluctuate widely in normal subjects. There were 2 post-toxemic hypertensives and 1 toxemia of pregnancy for which we offer a possible explanation in the Discussion below. The 2 cases of "renal impairment" had pyelonephritis. Ascending infections of the urinary tract are thought to permit increased back diffusion of urea through the tubular epithelium when inflammation involves these structures.

\section{DISCUSSION}

We have previously shown that the renal blood flow, as measured by the diodrast clearance, is normal during the hypertension found in the acute phases of the toxemias of pregnancy. As shown by the cases described above and summarized in Table II, many cases of post-toxemic hypertension fall in the normal range of renal blood flow (as does an occasional case of hypertension with no history of toxemia). When the renal blood flow is diminished in these cases, the decrease may perhaps be secondary to anatomical changes. In practically all of this group of patients, the hypertension is known to have existed for several years. This is partially indicated by the "years postpartum" column in Table II. All patients had had hypertension for the period indicated there (Section B), and many were known to have had hypertension antedating the most recent pregnancy from which " years postpartum" is reckoned. In brief, the hypertension in some cases does not seem to depend upon a reduction in the total volume of blood perfusing the kidneys. (Whether diminution in blood flow is the mechanism by which Goldblatt clamps cause hypertension is an open question. Apparently, there are no published data on the renal blood flow in Goldblatt animals in which the arterial constriction is just liminal.)

Moreover, diminished renal blood flow per se does not seem necessarily to result in hypertension, as witness the cases in Section C of Table II. There are complicating factors to be considered before drawing this conclusion. First, one may ask, is the renal extraction ratio for diodrast unchanged from the normally complete extraction? That is, does the diodrast clearance really measure the renal plasma flow in these cases of renal impairment? We can give no definite and direct answer to this question. Urea is excreted wholly by glomerular filtration, while diodrast is secreted chiefly by the tubules (at least 80 per cent by tubular secretion). Yet taking all of our cases together, over the very wide range of from 10 to 200 per cent of average normal renal function, the clearance of diodrast and of urea is closely parallel. This suggests a common controlling factor in the renal blood flow. In the dog the urea 
clearance parallels the renal blood flow, as Van Slyke, Rhoads and Hiller (9) have demonstrated. Furthermore, these subjects showed renal impairment by all tests of renal function, and it might be surmised that destruction of renal substance had occurred, thus necessarily reducing the blood flow and diodrast clearance.

Assuming a complete clearance of diodrast, the renal blood flow, then, would be markedly diminished in these patients with renal impairment. But is there renal ischemia in the sense that intact renal parenchyma is inadequately supplied with blood? Or is the renal blood flow merely lessened in proportion as renal parenchyma is destroyed, with the remaining tissue receiving a normal amount of blood? We have no answer for these questions. In glomerulonephritis it is probable that the glomerular lesions would impede the flow of blood and thus partially shut off the supply to the tubules. In the cases of post-toxemic renal damage, different glomerular lesions may cause the same thing to happen.

The glomerular lesion in toxemia of pregnancy has been described by Bell (10) as a thickening of the basement membrane in the glomerular capillaries. Baird and Dunn (11) have confirmed this, and recently Page and Cox (12) have found the same pathology persisting several years until death from various other causes. Possibly this thickening of the basement membrane may explain in part our findings in post-toxemic hypertensives. These findings include (1) renal ischemia when present, (2) the parallelism of the urea clearance (and glomerular filtration) with the renal blood flow, and (3) the not uncommon tendency of some of these patients to maintain for years a constant low level of renal function.

Since about one-fourth of the cardiac output perfuses the kidneys, which constitute less than 0.5 per cent of the body weight, the resistance here to blood flow must be relatively slight. If the glomerular capillaries were even slightly narrowed by the thickened basement membrane, the resistance to perfusion would be increased, and the total volume of fluid flow lessened. The minimum effect of such luminal narrowing of the capillaries may be approximated from Poiseuille's law which gives the volume $(Q)$ of fluid perfusing a capillary tube in unit time $(T)$ as:

$$
Q=\frac{\pi p r^{t}}{8 \ln } t
$$

where $p$ is the pressure decrement in the length (l) of the tube, the radius of which is $r$. $\eta$ is the coefficient of viscosity. The factors $\pi, 8 l$ and $t$ are, of course, constant. Assuming for the moment that $p$ and $\eta$ are also constant, a diminution of 10 per cent in the capillary diameter would decrease the blood flow by 35 per cent. The effective viscosity $(\eta)$ must be increased, which would reduce still more the blood flow. While Fåhraeus and Lindqvist (13) have shown that the coefficient of viscosity for blood decreases when the diameter of the tube falls below 0.3 mm., their data are not applicable to blood flow in capillaries where the diameter of the red blood corpuscles so closely approaches the diameter of the vessel that smoothly moving concentric layers cannot be formed with the cells in the axial stream (14). The narrowing of the capillaries may, perhaps, be partially offset by a greater pressure decrement. When the compensation is not complete, a decrease in blood flow would result. We shall return to this factor presently.

Thus any appreciable narrowing of the capillaries may be presumed to diminish the volume of blood circulation. This would account for the renal ischemia, when ischemia is present. Since the ischemia does not seem to be caused by, or associated with, constriction of the efferent glomerular arteriole, intra-glomerular pressure is not markedly increased, the filtration fraction remains normal, and the glomerular filtration (and urea clearance) varies with the renal blood flow. Two of our 14 post-toxemic hypertensives do show high filtration fractions, but the usual case apparently does not conform with Smith's findings in male hypertensives.

As for the third observation, which may be explained on the basis of the thickened basement membrane, most of the patients in Sections B and C of Table II, as well as many others not included in this study, have been followed for several years ; in that time the renal functional levels have either not changed at all, or have shown very slow improvement. This has been found in patients with urea clearances as low as 20 per cent, and the clearances have remained at that level for as long as 5 years. When the urea clearance falls as low 
as 20 per cent in chronic glomerulonephritis or in nephrosclerosis, the renal lesion progresses. In acute nephritis the lesion either regresses or goes on to a fatal outcome. Conceivably, during toxemia of pregnancy the glomerular lesion is produced. With termination of the pregnancy, and of the toxemia, further damage to the glomerular capillaries does not occur and renal function becomes stabilized. In a few cases a very slow improvement in function may occur; in some malignant nephrosclerosis supervenes (15). Some of our cases have been reviewed elsewhere (16) in another connection, and without consideration of the specific lesion which may underlie the deficit in kidney function.

It would appear from the above considerations that post-toxemic hypertension is often on a different basis from the hypertension found in men (Smith) and in some women who have not had toxemia of pregnancy (Section A, Table II), though the dividing line is not a hard and fast one. Therapeutic measures designed to relax the constriction in the efferent glomerular arteriole may be beneficial in the latter group. Perhaps such treatment would be ineffective in posttoxemic hypertensives.

Arterial hypertension has often been regarded as a compensatory mechanism which maintains a relatively normal glomerular filtration either in the face of a deficit in renal flow, or by increasing the volume of blood perfusing the kidney. In the first case, if the increased systemic blood pressure is reflected in an increased intra-glomerular pressure, the filtration fraction should be increased. This factor, together with efferent arteriolar constriction, has been mentioned by Smith as accounting for the high filtration fractions seen in male hypertensives. In the second case, if hypertension increases the renal blood flow by driving the blood through the kidney at an increased rate, and by providing a high head of pressure permitting of an increased decrement ( $p$ in Poiseuille's equation), one may conceive that the filtration fraction might not be increased, even with a high intra-glomerular pressure. The plasma in a given volume of blood may simply be too short a time in contact with the filtering surface if the resistance to flow is not distal to the glomerulus. Yet, because of the increased volume of blood passing through the glomerular capil- laries, the total filtration is increased by hypertension. While a quantitative separation of these two effects of hypertension is impossible, it may be that each of our 2 groups of hypertensives shows predominantly one and the other of these compensatory mechanisms. The patients of Section A of Table II and the male hypertensives described by Smith (8) show high filtration fractions. The constriction of the efferent glomerular arteriole imposes a resistance to blood flow distal to the glomerulus, and thus slows the rate of flow through the glomerular capillaries. The arterial hypertension reflected in increased intraglomerular pressure raises the filtration. In the post-toxemic hypertensives, the resistance to perfusion may be in the glomerular capillaries whose lumina are narrowed by the thickened basement membrane. Hence, it is through the capillaries that the blood must flow most rapidly. Hypertension may be the propulsive force which keeps the total volume normal, or nearly so, by speeding the flow through the point of resistance. The filtration which occurs through the capillary walls may be lessened because of the thickened filter. Because of this and because of the shorter time of contact of a unit volume of plasma with the filter, the filtration fraction tends to fall, but the tendency is offset by the higher pressure. Hypertension thus maintains the glomerular filtration at normal levels by opposing the resistance to perfusion and thus increasing the renal blood flow.

Finally, it is worth mention that, except in certain cases of essential hypertension, the urea clearance is as good a test of renal function as is the diodrast clearance. The more one uses the urea clearance, the more one is impressed with its clinical value. As has long been known, the urea clearance usually is proportional to the glomerular filtration and therefore gives an estimate of glomerular function. As our data demonstrate, the urea clearance also will give an estimate of the renal blood flow. Landis, Elsom, Bott and Shiels (17) have shown the same parallelism between the plasma clearances of urea and hippuran, the latter of which approaches the complete clearance of diodrast.

\section{SUMMARY AND CONCLUSIONS}

Using the diodrast clearance, indirect measurements of the effective renal blood flow have been 
made in a series of 37 women having hypertension and renal impairment occurring separately and together.

Hypertension sometimes occurs with a normal total renal blood flow. In other cases, the deficit in renal blood flow is only slight and may perhaps be secondary to anatomical changes produced by the long-standing hypertension.

In the majority of patients having " essential " hypertension the renal blood flow, as measured by the diodrast clearance, is considerably reduced below average normal. Such deficit in total renal blood flow seems often to be associated with efferent glomerular arteriolar constriction and, consequently, with a high filtration fraction which may maintain " normal renal function" by tests other than the diodrast clearance.

In the hypertension seen in women who have had toxemia of pregnancy as the initial phase of the hypertension, the filtration fraction is usually normal. It is suggested that the glomerular capillaries rather than the efferent arterioles are the site of resistance to blood flow in these cases.

The urea clearance often parallels the renal blood flow. The exception is found in those cases where efferent glomerular arteriolar constriction exists. In 70 subjects, the coefficient of correlation between the urea clearance and blood flow is 0.79 .

Marked diminution in renal blood flow, as measured by the diodrast clearance, may be found in patients with normal blood pressures. Since destruction of the renal parenchyma may have occurred, renal ischemia may not be present in these cases.

We gratefully acknowledge our indebtedness to Drs. S. A. Cosgrove, J. F. Norton, and E. G. Waters for reading the typescript and for permission to use patients from their services. Dr. M. Bresev of the Jersey City Medical Center selected for us many of the patients with hypertension without history of toxemia of pregnancy. Many of the blood and urine urea determinations were made by Frances Orsato and Peter Marotta.

\section{BIBLIOGRAPHY}

1. Fishberg, A. M., Hypertension and Nephritis. Lea and Febiger, Philadelphia, 1934, 3d ed.

2. Goldblatt, H., Experimental hypertension induced by renal ischemia ; Harvey Lecture. Bull. New York Acad. Med., 1938, 14, 523.

3. Boyd, C. H., and Lewis, L. G., Nephrectomy for arterial hypertension; preliminary report. J. Urol., 1938, 39, 627.

4. Smith, H. W., Goldring, W., and Chasis, H., The measurement of the tubular excretory mass, effective renal blood flow and filtration rate in the normal human kidney. J. Clin. Invest., 1938, 17, 263.

5. Chesley. L. C., and Chesley, E. R., The diodrast clearance and renal blood flow in normal pregnant and non-pregnant women. Am. J. Physiol., 1939, 127, 731.

6. Chesley, L. C., Connell, E. J., Chesley, E. R., Katz, J. D., and Glissen, C. S., The diodrast clearance and renal blood flow in toxemias of pregnancy. J. Clin. Invest., 1940, 19, 219.

7. Peters, J. P., and Van Slyke, D. D., Quantitative Clinical Chemistry. Vol. II. Methods. Williams and Wilkins Co., Baltimore, 1932, pp. 360-379, 684.

8. Smith, H. W., Studies in the physiology of the kidney; Porter Lectures. University Extension Division, University of Kansas, Lawrence, 1939.

9. Van Slyke, D. D., Rhoads, C. P., Hiller, A., and Alving, A. S., The relationship of the urea clearance to the renal blood flow. Am. J. Physiol., 1934, 110, 387.

10. Bell, E. T., Renal lesions in toxemias of pregnancy. Am. J. Path., 1932, 8, 1.

11. Baird, D., and Dunn, J. S., Renal lesions in eclampsia and nephritis of pregnancy. J. Path. and Bact., 1933, 37, 291.

12. Page, E. W., and Cox, A. J., Renal changes following toxemias of late pregnancy. West. J. Surg., 1938, 46, 463.

13. Fåhraeus, R., and Lindqvist, $T$., The viscosity of the blood in narrow capillary tubes. Am. J. Physiol., 1931, 96, 562.

14. Landis, E. M., Poiseuille's law and the capillary circulation. Am. J. Physiol., 1933, 103, 432.

15. McKelvey, J. L., and MacMahon, H. E., A study of the lesions in the vascular system in fatal cases of chronic nephritic toxemia of pregnancy. Malignant nephrosclerosis. Surg., Gynec. and Obst., 1935, 60, 1.

16. Chesley, L. C., Renal function tests in the differentiation of Bright's disease from so-called specific toxemia of pregnancy. Surg., Gynec. and Obst., 1938, 67, 481.

17. Landis, E. M., Elsom, K. A., Bott, P. A., and Shiels, E. H., Simultaneous plasma clearances of creatinine and certain organic compounds of iodine in relation to human kidney function. J. Clin. Invest., 1936, 15, 397. 